\section{Enjuagatorios bucales como medida preventiva en la atención odontológica durante pandemia por COVID-19}

\author{
Mouthwashes as a preventive measure in \\ dental care during a COVID-19 pandemic
}

\section{Sr. Editor.}

Debido a la propagación del COVID-19, han surgido nuevos protocolos de atención odontológica para poder controlar esta pandemia. Se sabe que una de las principales formas de ingreso del SARS-CoV-2 a nuestro organismo es a través de la cavidad bucal ya que las glándulas salivales menores y botones gustativos están cargados de receptores ACE- $2{ }^{1}$. Por eso, consideramos que es importante fomentar el uso de enjuagues bucales preoperatorios durante la consulta odontológica para reducir la carga viral en boca y así prevenir la propagación de este virus entre el paciente y el operador. La presente carta al editor tiene como objetivo fundamentar la importancia del uso de estos colutorios.

Varios autores han recomendando enjuagues a base de yodo povidona al $1 \%$, peróxido de hidrógeno al $0,5 \%-1 \%$, y CPC al $0,05-0,1 \%{ }^{2,3}$. Sin embargo, los dos primeros tienen algunas desventajas como el mal sabor, posible alergia al yodo, falta de conocimiento en su dilución y por ende, riesgo de quemaduras de la mucosa oral, etc. Por otro lado, en un estudio compararon la eficacia frente al SARS-CoV-2 de enjuagues bucales a base de agua oxigenada al 1,5\% y 3\%; y yodo povidona al 0,5\%, 1,25\% y $1,5 \%$. Encontraron que solo los enjuagues a base de yodo povidona en las 3 concentraciones reducían considerablemente la carga viral en la cavidad oral ${ }^{3}$. Por este motivo, recomendamos hacer más estudios respecto a lo anterior, ya que, debido al bajo costo del agua oxigenada, la mayoría de odontólogos lo usa como medida preventiva antes de los procedimientos dentales.

Por otro lado, Yoon y cols ${ }^{4}$. encontraron que el uso de enjuagues bucales con clorhexidina al $0,12 \%$ son efectivos para reducir, por un periodo de 2 horas, la carga viral presente en la saliva de pacientes con COVID-19. Este último estudio nos resalta la importancia del uso de enjuagues bucales como método preventivo en la atención odontológica durante esta

\section{Carta al Editor}

Gabriel Pérez-Mejía ${ }^{1, a}$, Lohana Herencia-Torres ${ }^{1, a}$, Kamila Sihuay-Torres ${ }^{2, b}$

${ }^{1}$ Universidad Nacional San Luis Gonzaga, Sociedad Científica de Estudiantes de Odontología, Ica, Perú. 2 Universidad Nacional Mayor de San Marcos, Maestría en Salud Pública, Escuela de Postgrado de la Facultad de Medicina Humana, Lima, Perú.

a Estudiante del pregrado.

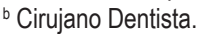

\section{Correspondencia:}

Gabriel Pérez-Mejía: perezmejiagabriel@gmail.com Urb. Santo Domingo de Marcona C-9. Ica, Perú. ORCID: 0000-0002-4321-9622

\section{Coautores:}

Lohana Herencia-Torres: herenciatorreslohana@gmail.com ORCID: 0000-0002-4679-6986

Kamila Sihuay-Torres: kamila.sihuay28@gmail.com ORCID: 0000-0001-5247-2454

Conflicto de intereses: los autores declaran no tener conflictos de interés.

Recibido: 25/11/20

Aprobado: $18 / 01 / 21$

Publicado: 01/04/21 
pandemia. Además, de acuerdo a estudios realizados in vitro, se ha demostrado que enjuagues bucales que contienen CPC al 0,05\% - 0,1\% pueden inhibir la actividad de virus similares al SARS-CoV-2, los cuales están presentes en la cavidad oral. Esto se da por la presencia de agentes oxidativos que actúan destruyendo la capa protectora lipídica que envuelve al virus. Cabe resaltar que su acción en la cavidad oral dura entre 3 a 5 horas ${ }^{5,6}$.

Debido a las desventajas del uso de enjuagues bucales a base de peróxido de hidrógeno y yodo povidona, consideramos que es importante hacer hincapié en el uso preoperatorio de enjuagues bucales que contengan clrorhexidina al $0,12 \%$ o CPC para reducir la carga viral presente en la saliva. La mayoría de enjuagues bucales que contienen CPC presentan una concentración del $0.05 \%$ dependiendo de la marca y el laboratorio en el que se fabrica. Se recomienda utilizar $15 \mathrm{ml}$ de enjuague bucal por 30 segundos como mínimo antes de la atención odontológica, haciendo gárgaras y sin enjuagar después de su uso. Su uso preventivo en la consulta se indica a partir de los 6 años, en niños más pequeños se podría utilizar solo en caso tenga la enfermedad. Por otro lado, recomendamos la lectura de las indicaciones brindadas por el fabricante.

Conociendo las ventajas y propiedades del uso de enjuagues bucales a base de clorhexidina y CPC, consideramos que es importante difundir la información entre odontólogos para fomentar su uso preoperatorio. Estos colutorios no solo permiten controlar la carga bacteriana sino también inhibir a varios virus muy similares al SARS-CoV-2 lo cual sería de gran ayuda para una correcta atención dental. Recalcamos su uso como un método preventivo preoperatorio dentro de los protocolos de atención para combatir esta enfermedad.

\section{Referencias bibliográficas}

1. Xu H, Zhong L, Deng J, Peng J, Dan H, Zeng X, et al. High expression of ACE2 receptor of 2019-nCoV on the epithelial cells of oral mucosa. Int J Oral Sci. 2020;12(8). DOI: https://doi.org/10.1038/s41368-020-0074-x

2. Li ZY, Meng LY. The prevention and control of a new coronavirus infection in department of stomatology. Zhonghua Kou Qiang Yi Xue Za Zhi. 2020;55(0):E001. DOI: 10.3760/cma.j.issn.1002-0098.2020.0001

3. Bidra AS, Pelletier JS, Westover JB, Frank S, Brown SM, Tessema B. Comparison of In Vitro Inactivation of SARS CoV-2 with Hydrogen Peroxide and Povidone-Iodine Oral Antiseptic Rinses. J Prosthodont. 2020;29:599603. DOI: $10.1111 /$ jopr. 13220

4. Yoon JG, Yoon J, Song J, Yoon S, Lim C, Seong H, et al. Clinical Significance of a High SARS-CoV-2 Viral Load in the Saliva. J Korean Med Sci. 2020;35(20):e195. DOI:10.3346/jkms.2020.35.e195

5. Popkin D, Zilka S, Dimaano M, Fujioka H, Rackley C, Salata R, et al. Cetylpyridinium Chloride (CPC) Exhibits Potent, Rapid Activity Against Influenza Viruses in vitro and in vivo. Pathog Immun. 2017;2(2):252-269. DOI: https://doi:10.20411/pai.v2i2.200

6. Mukherjee PK, Esper F, Buchheit K, Arters K, Adkins I, Ghannoum MA, et al. Randomized, double-blind, placebo-controlled clinical trial to assess the safety and effectiveness of a novel dual-action oral topical formulation against upper respiratory infections. BMC Infect Dis. 2017;17:74. DOI: https://10.1186/s12879-016-2177-8 